\title{
PROCESO DE EXAMINACIÓN DEL CSE: INCIDENCIA DE LA VARIABLE GÉNERO EN EL RENDIMIENTO ACADÉMICO
}

\author{
Nelson Paulus* \\ Thomas Griggs*
}




\title{
RESUMEN
}

Este artículo da cuenta de un estudio que pretende discriminar, en el contexto de los procesos de examinación Modalidad Tres que ha aplicado el Consejo Superior de Educación a algunas de las instituciones que están adscritas al proceso de acreditación en los años 2001 y 2002, el comportamiento de la variable género en el rendimiento académico de los alumnos. Estas diferencias se expresan de diversa manera, dependiendo del tipo de instituciones examinadas, de la jornada a la cual pertenezcan los alumnos examinados, del tipo de asignaturas y del tipo de carrera que se haya examinado.

Las conclusiones llaman la atención acerca de la existencia de algunos fenómenos, comunes a ambos géneros, que deberían generar preocupación al interior de las instituciones que imparten enseñanza de nivel superior.

\begin{abstract}
This paper describes a study that attempts to discriminate -in the context of the Type Three examination processes applied by the Higher Education Council to some of the institutions that signed up for the accreditation process in 2001 and 2002- how the gender variable behaves in terms of the students' academic performance. Differences are expressed in dissimilar ways, depending on the type of institution examined, the school shift attended by students, the type of subjects involved, and the kind of study program examined.

The conclusions draw attention to the existence of certain observable facts, common to both genders, that should be cause for concern among higher education establishments.
\end{abstract}




\section{PROCESO DE EXAMINACIÓN DEL CSE: INCIDENCIA DE LA VARIABLE GÉNERO EN EL RENDIMIENTO ACADÉMICO}

I. Presentación y consideraciones metodológicas del estudio

Los datos que sirven de base a este estudio fueron obtenidos de la aplicación de uno de los procedimientos que establece la Ley Orgánica Constitucional de Enseñanza, $N^{\circ} 18.962$ (LOCE), para materializar el proceso de acreditación que la mencionada ley le encomienda al Consejo Superior de Educación. Al respecto, cabe señalar que este procedimiento se encuentra establecido en los artículos 37 letra c) y 41 de la referida ley, los que señalan que al Consejo "...le corresponde establecer sistemas de examinación selectiva para las instituciones de educación superior sometidas a procesos de acreditación, con el objeto de evaluar el cumplimiento de los planes y programas de estudio y el rendimiento académico de los alumnos".

Para la implementación de este procedimiento, el Consejo ha definido tres modalidades de examinación, dentro de las cuales la Modalidad Tres es la única que tiene resultados vinculantes en la aprobación o reprobación de los alumnos de la respectiva asignatura que una institución imparta. Para la realización de esta examinación, el Consejo designa consultores expertos, quienes diseñan, evalúan y califican por sí solos los exámenes, y los profesores titulares de las asignaturas evaluadas pueden, previo a su aplicación, efectuar las recomendaciones que estimen convenientes, a través de un informe escrito referido a la estructura y contenidos del examen.

Para la elaboración del examen, el evaluador contratado por el Consejo tiene a la vista un conjunto de antecedentes que le permiten 
conocer la forma y profundidad con que el curso fue impartido: la malla curricular de las carreras que se examinan, el programa de las asignaturas evaluadas -que incluye una descripción detallada de objetivos, contenidos y bibliografía exigida y recomendada- y un informe escrito por parte de los profesores de las asignaturas impartidas en los respectivos semestres, que señala los contenidos programáticos tratados en forma más relevante en el desarrollo de la asignatura y que contiene una propuesta de la estructura del examen (preguntas de desarrollo, selección múltiple u otra).

Una vez finalizado el proceso de examinación, esto es, aplicados los exámenes de primera oportunidad (y los de segunda en el caso de aquellas entidades cuyos reglamentos así lo disponen), el Consejo remite a las instituciones los exámenes corregidos y las pautas de evaluación, además, claro está, de las actas de notas respectivas. Sin perjuicio de ello, los resultados de la examinación son informados mediante oficio, en el cual se consignan las principales observaciones y sugerencias que se derivan del proceso.

Este estudio pretende discriminar, en el contexto de los procesos de examinación Modalidad Tres que ha aplicado el Consejo Superior de Educación a algunas de las instituciones que están adscritas al proceso de acreditación -en los años 2001 y 2002-, el comportamiento de la variable género en el rendimiento académico de los alumnos.

Con el objeto de observar con mayor precisión y detalle la incidencia de la variable género en el rendimiento académico de los alumnos, se ha resuelto incorporar al análisis un conjunto de otras variables que pueden influir en el referido rendimiento:

- Tipo de institución examinada.

- Jornada horaria a la que asisten los alumnos evaluados.

- Área disciplinaria a la que pertenece la carrera evaluada.

- Área disciplinaria a la que pertenece la asignatura examinada.

El rendimiento académico, por su parte, será medido a través de los siguientes indicadores:

- Promedio de las notas de presentación al examen.

- Promedio de las notas obtenidas en el examen de primera oportunidad. 
- Porcentaje de alumnos que aprueban el examen de primera oportunidad.

Cada uno de estos indicadores será cruzado con la variable género, detallando el análisis conforme a las demás variables que ya se mencionaron.

Hipótesis del estudio

Existen diferencias significativas entre los rendimientos obtenidos por las mujeres y los hombres, en el marco de los procesos de examinación que aplica el Consejo Superior de Educación. Estas diferencias se expresan de diversa manera, dependiendo del tipo de instituciones examinadas, de la jornada a la cual pertenezcan los alumnos examinados, del tipo de asignaturas y del tipo de carrera que se haya examinado.

\section{Metodología}

En este estudio se espera determinar la relación entre dos variables: género y rendimiento. Hay que tener presente, sin embargo, que ambas variables son de diferente naturaleza, pues la primera corresponde a una variable nominal que reconoce sólo clasificación en categorías (mujer y hombre), mientras que la segunda constituye una variable de intervalo que, además de reconocer categorías, asume valores de intensidad (menor-mayor). Además de demostrar la existencia de una relación entre dichas variables, este estudio pretende determinar el sentido de esa relación, dada la característica de nominalidad discreta de la variable género.

Por otra parte, cabe señalar, a modo de consideración preliminar, que dentro del sistema educativo chileno las notas asignadas van desde 1,0 a 7,0, ordenándose sus distribuciones a partir de variaciones decimales. La forma en la cual se asigna dicha calificación varía en las distintas asignaturas, carreras, profesores, etc.; de manera que, a pesar de que en el sistema educacional hay acuerdos básicos y tácitos respecto a lo que significa un 1,0 y un 7,0, no siempre se obtiene el mismo nivel de acuerdo, por ejemplo, respecto al valor de un 4,0. En este contexto, omitiendo las consideraciones acerca del significado interno 
de cada una de las calificaciones, en este estudio se utiliza como componente uniformador la calificación asignada asociada a la escala de notas utilizadas y reconocida por el sistema educacional chileno, el cual reconoce como nota mínima de aprobación la nota 4,0 .

En cuanto a la variable género, es necesario señalar que ésta se obtuvo a partir de una codificación manual de los nombres de los estudiantes registrados, asignando la variable en función del nombre del estudiante examinado. Esta labor no estuvo exenta de problemas, particularmente en el caso de aquellos alumnos cuyos nombres no implican necesariamente una asignación inequívoca. Por otra parte, se presentaron casos en los cuales el nombre del estudiante examinado, dado su origen extranjero, no permitió asignar claramente un género. En estos casos, y dado que el porcentaje de éstos representa sólo un 0,34\% de la muestra, se optó por omitirlos en el análisis.

La definición de las variables utilizadas en el estudio es la siguiente:

a) Género: sexo del estudiante examinado.

b) Rendimiento: resultado académico obtenido por el alumno, el que se mide a través de los siguientes indicadores:

- Porcentaje de aprobación del primer examen: porcentaje de los alumnos examinados que obtiene nota igual o superior a 4,0 en la primera prueba aplicada ${ }^{2}$ por el CSE.

- Nota de presentación: nota promedio de presentación de los alumnos examinados.

- Nota primer examen: nota obtenida por el alumno en el examen aplicado por el Consejo en primera oportunidad.

c) Tipo de institución: entidad en la que estudia el alumno examinado, pudiendo ser ésta una universidad o un instituto profesional.

d) Área de carrera: área temática de la carrera en la que estudia el alumno examinado. Éstas áreas son: Administración, Arte y Arquitectura, Agropecuaria, Derecho, Ciencias Sociales, Ciencias, Tecnología, Educación, Humanidades y Salud.

1 Para el caso de la obtención de promedios se expresan los puntos y un decimal, no obstante lo cual, para la obtención de este último, se considera la aproximación desde el segundo decimal en la medida que este es igual o superior a 0,05 .

2 En el caso de las instituciones que no contemplan examen de repetición, corresponde al examen único aplicado. 
e) Tipo de asignatura: área disciplinaria de la asignatura en la que estudia el alumno examinado. Al respecto, se han establecido para los efectos de este estudio los siguientes tipos de áreas disciplinarias: Administración, Auditoría y Contabilidad; Ciencias Básicas, Ciencias Sociales, Computación, Derecho, Economía, Educación, Humanidades, Letras, Matemáticas y Psicología.

f) Jornada: horario de la carrera en la que estudia el alumno examinado, pudiendo ser diurna o vespertina. Por jornada vespertina se entiende toda aquella jornada horaria que se inicia después de las 18:00 hrs., juzgando que ese es un horario compatible con la mayoría de las actividades laborales. Todas las carreras cuyas actividades docentes se inician antes de esa hora se consideran en este estudio como diurnas.

Como se mencionó, los registros utilizados en el análisis corresponden a los alumnos evaluados en el contexto de las examinaciones Modalidad Tres, aplicadas por el Consejo Superior de Educación a sus instituciones durante el primer y segundo semestre de los años 2001 y 2002. Los datos que sirven de base para este estudio fueron obtenidos en el marco de los procesos de supervisión que implementa el Consejo Superior de Educación, y que tienen como objetivo evaluar el rendimiento académico de los alumnos y la calidad y efectividad de los programas de estudio implementados. Como un objetivo secundario se han empleado estos datos para la elaboración de este estudio, por lo que se puede sostener que éste tiene un diseño no experimental que, a partir de datos ya obtenidos en otro contexto, pretende describir una realidad precisa.

En consideración a estas razones, este estudio no pretende extrapolar sus resultados a otros contextos que no sean los de las instituciones, carreras y asignaturas examinadas, pues la construcción de los datos que lo nutren no es probabilística ni representativa.

No obstante, este estudio puede ser utilizado para ejemplificar la incidencia de la variable género en el rendimiento académico de un grupo delimitado de alumnos, lo que puede orientar las interrogantes que se relacionen con este tema y que se sitúen en contextos distintos de los de este estudio. 
Marco general de la muestra

En el contexto de los procesos de examinación que enmarcan el desarrollo de este estudio, correspondía evaluar a un total de 11.154 alumnos, lo que corresponde al número de estudiantes inscritos en las asignaturas y que tenían derecho de rendir su examen. De esos, fueron efectivamente examinados $10.941^{3}$ alumnos, equivalentes a un $98,1 \%$ del total. Esta diferencia se explica porque, por diversos motivos, algunos de ellos no se presentaron en la oportunidad en que se tomó el examen. Además, cabe señalar que todos los datos que aquí se consignan corresponden a los exámenes aplicados en primera oportunidad, ya que la segunda oportunidad sólo se rinde en instituciones cuyos reglamentos académicos contemplan esta instancia, por lo que, si se incluyera, la muestra no resultaría representativa del universo evaluado.

Asimismo, al referirse a "alumnos efectivamente examinados", se está haciendo alusión a los exámenes aplicados, revisados y calificados, por lo que, en varios casos, hay alumnos que fueron examinados en más de una oportunidad, en diversas asignaturas y en diferentes momentos. No obstante lo anterior, para efectos de simplificar la expresión, nos referimos a "alumnos efectivamente examinados" para aludir el número de exámenes rendidos por los alumnos.

Del total de los alumnos efectivamente examinados un $27,1 \%$ cursaba estudios en un instituto profesional y el $72,9 \%$ en una universidad. Además, del total examinado, un $68,7 \%$ cursaba estudios en jornada diurna y un $31,3 \%$ en vespertina.

De los 11.154 alumnos que debían rendir exámenes, 6.138 son mujeres y 5.016 hombres, lo que representa un 55\% y $45 \%$, respectivamente.

3 Se entenderá como alumno efectivamente examinado a todos aquel que, en a lo menos una oportunidad (considerando las instituciones que contemplan exámenes de repetición), se haya presentado y haya rendido un examen aplicado por el CSE, en el contexto del correspondiente proceso de examinación Modalidad Tres, situación por la cual el CSE le haya asignado una calificación. 
Por su parte, de los alumnos efectivamente examinados en los institutos profesionales, un $37 \%$ corresponde a mujeres, mientras que en las universidades las mujeres representan un $61,7 \%$ de los examinados.

Con el objeto de comparar las notas promedio de presentación y las notas obtenidas en el primer examen, se toma como base los 10.941 exámenes rendidos por los alumnos en primera oportunidad.

\section{Desarrollo del Estudio}

a) Notas promedio de presentación (N.P.) y de primer examen (N.E.1) según género y tipo de institución.

Tabla $\mathrm{N}^{\circ} 1$

\begin{tabular}{|l|l|c|c|}
\hline Tipo institución & Datos & Femenino & Masculino \\
\hline Institutos Profesionales & Promedio de N.P. & 5,0 & 4,9 \\
& Promedio de N.E.1 & 3,4 & 3,2 \\
\hline Universidades & Promedio de N.P. & 5,0 & 4,5 \\
& Promedio de N.E.1 & 3,8 & 3,5 \\
\hline Total Promedio de N.P. & & 5,0 & 4,6 \\
\hline Total Promedio de N.E.1 & & 3,7 & 3,4 \\
\hline
\end{tabular}

Con relación a las notas promedio de presentación a examen, se observa que, en términos generales, las mujeres presentan, en promedio, 4 décimas de punto más que los hombres, obteniendo una nota promedio de 5,0. En el caso de aquellas alumnas que cursan estudios en institutos profesionales, esta diferencia es aún menor y alcanza 1 décima de punto en relación con sus compañeros hombres, mientras que en el caso de las alumnas universitarias la diferencia es mayor y llega a las 5 décimas, de lo que se puede rescatar, como primera consideración, que las mujeres obtienen, a lo largo del semestre, calificaciones que son superiores a las obtenidas por sus compañeros hombres, situación que se da tanto en las universidades como en los institutos profesionales. Sin embargo, esta diferencia es muy menor en el caso de éstas últimas instituciones donde el rendimiento de ambos géneros es casi igual. 
En relación con las notas obtenidas en el primer examen aplicado por el Consejo Superior de Educación, se observa que las alumnas obtienen una diferencia de tres décimas de punto respecto de sus compañeros hombres. Las alumnas evaluadas que pertenecen a institutos profesionales obtienen dos décimas de punto más que aquellos. En las universidades esta diferencia es mayor en tres décimas de punto. Por lo tanto, una vez finalizado el semestre, las mujeres nuevamente obtienen un rendimiento superior al de los hombres, situación que se observa en universidades e institutos profesionales.

Por otra parte, se puede observar que la brecha entre la nota promedio de presentación y la nota obtenida en el examen es casi igual entre ambos géneros, siendo levemente mayor en el caso de las mujeres, alcanzando, en total, 1,3 puntos, frente a la diferencia de 1,2 puntos que presentan los hombres. Esto podría indicar que las mujeres tienen un rendimiento superior a los hombres durante el semestre, sin embargo, en las evaluaciones finales no consiguen confirmar ese rendimiento. Los hombres en cambio, muestran un rendimiento más bien deficitario en las evaluaciones parciales, mejorando de manera relativa su rendimiento en los exámenes finales. En todo caso, esto es sólo una indicación que no puede ser presentada como conclusión general del estudio, pues la diferencia entre ambos indicadores es muy menor.

Sin perjuicio de lo anterior, se observa que las alumnas pertenecientes a institutos profesionales muestran una brecha levemente menor, y en los exámenes aplicados obtuvieron notas más cercanas a sus promedios de presentación, mientras que los hombres mostraron una diferencia mayor. En este sentido, las mujeres muestran una diferencia de 1,6 puntos, mientras que los hombres de 1,7. En el caso de las universidades la situación se revierte y las mujeres muestran una diferencia mayor en comparación a los hombres: 1,2 y 1 punto, respectivamente.

Como observación general se puede señalar que la diferencia entre ambos indicadores es mayor en los institutos profesionales que en las universidades, por lo que se podría sostener que mujeres y hombres que cursan una carrera en una universidad obtienen, en sus exámenes de primera oportunidad, resultados más cercanos al rendimiento obtenido en el semestre, a diferencia de los alumnos de institutos profesionales donde esta diferencia es mayor. 
b) Notas de presentación y de primer examen por género, tipo de institución y jornada.

Tabla $\mathrm{N}^{\circ} 2$

\begin{tabular}{|c|c|c|c|c|}
\hline Jornada & Tipo Institución & Datos & Femenino & Masculino \\
\hline \multirow{4}{*}{ Diurna } & \multirow[t]{2}{*}{ Institutos Profesionales } & Promedio de N.P. & 5,1 & 4,9 \\
\hline & & Promedio de N.E.1 & 3,5 & 3,1 \\
\hline & \multirow[t]{2}{*}{ Universidades } & Promedio de N.P. & 5,0 & 4,5 \\
\hline & & Promedio de N.E.1 & 3,9 & 3,6 \\
\hline \multicolumn{3}{|c|}{ Promedio de N.P. Diurna } & 5,0 & 4,6 \\
\hline \multicolumn{3}{|c|}{ Promedio de N.E.1 Diurna } & 3,8 & 3,4 \\
\hline \multirow{4}{*}{ Vespertina } & \multirow[t]{2}{*}{ Institutos Profesionales } & Promedio de N.P. & 4,9 & 4,8 \\
\hline & & Promedio de N.E.1 & 3,2 & 3,3 \\
\hline & \multirow[t]{2}{*}{ Universidades } & Promedio de N.P. & 4,9 & 4,5 \\
\hline & & Promedio de N.E.1 & 3,6 & 3,5 \\
\hline \multicolumn{3}{|c|}{ Promedio de N.P. Vespertina } & 4,9 & 4,7 \\
\hline \multicolumn{3}{|c|}{ Promedio de N.E.1 Vespertina } & 3,5 & 3,4 \\
\hline \multicolumn{3}{|c|}{ Total Promedio de N.P. } & 5,0 & 4,6 \\
\hline \multicolumn{3}{|c|}{ Total Promedio de N.E.1 } & 3,7 & 3,4 \\
\hline
\end{tabular}

Si se analizan los datos tomando en consideración la jornada horaria a la que asisten los distintos alumnos examinados, se observa que las alumnas superan, en ambas jornadas, el rendimiento académico de los hombres, tanto el mostrado durante el semestre como el obtenido en los exámenes aplicados por el Consejo. Sin embargo, la diferencia es mayor en la jornada diurna, en la cual la nota promedio de presentación de las mujeres supera en 0,4 puntos a las de los hombres. La misma diferencia se observa en los promedios de las notas obtenidas en los exámenes.

En la jornada vespertina se observa una diferencia que también es favorable a las mujeres, sin embargo, es menor que la observada en la jornada diurna. En efecto, las notas promedio de presentación a examen son superiores en el caso de las mujeres en 0,2 puntos, y la diferencia entre las notas obtenidas en el examen es sólo de una décima de punto.

Cabe señalar que una excepción a esta tendencia se observa en las carreras de institutos profesionales en jornada vespertina, donde los hombres obtuvieron en sus exámenes un promedio superior en 0,1 puntos al promedio obtenido por las mujeres. 
El extremo opuesto se observa en el caso de las notas promedio de presentación de las mujeres que estudian en universidades en jornada diurna, las que se imponen con una diferencia contundente frente a los hombres: 0,5 puntos.

Finalmente, se puede señalar que la diferencia entre las notas promedio de presentación a examen y las notas obtenidas en éste son relativamente similares entre mujeres y hombres en ambas jornadas. En el caso de la jornada diurna la diferencia es la misma: 1,2 puntos; pero en la jornada vespertina esta diferencia resulta levemente favorable a los hombres: 1,3 y 1,4 puntos, respectivamente.

c) Notas de presentación y de primer examen por género y área de la carrera.

Tabla $N^{\circ} 3$

\begin{tabular}{|l|l|c|c|}
\hline Área carrera & Datos & Femenino & Masculino \\
\hline Administración & Promedio de N.P. & 4,6 & 4,6 \\
& Promedio de N.E.1 & 3,2 & 3,2 \\
\hline \multirow{2}{*}{ Agropecuaria } & Promedio de N.P. & 4,7 & 4,7 \\
& Promedio de N.E.1 & 3,1 & 3,2 \\
\hline Arte y Arquitectura & Promedio de N.P. & 5,0 & 4,7 \\
& Promedio de N.E.1 & 3,8 & 4,0 \\
\hline Ciencias Sociales & Promedio de N.P. & 5,0 & 4,7 \\
& Promedio de N.E.1 & 3,9 & 3,8 \\
\hline Derecho & Promedio de N.P. & 4,5 & 4,5 \\
& Promedio de N.E.1 & 3,8 & 3,7 \\
\hline Educación & Promedio de N.P. & 5,4 & 5,1 \\
& Promedio de N.E.1 & 4,0 & 4,1 \\
\hline Humanidades & Promedio de N.P. & 5,3 & 5,3 \\
& Promedio de N.E.1 & 4,5 & 4,9 \\
\hline Tecnología & Promedio de N.P. & 4,6 & 4,5 \\
& Promedio de N.E.1 & 2,7 & 2,8 \\
\hline Total Promedio de N.P. & & 5,0 & 4,6 \\
\hline Total Promedio de N.E.1 & & 3,7 & 3,4 \\
\hline
\end{tabular}


Si se incorpora al análisis el área disciplinaria de la carrera que estudian los alumnos examinados, se observa que las notas promedio de presentación son, en general, más altas en las mujeres que en los hombres, lo que se advierte en las áreas de Arte y Arquitectura, Ciencias Sociales, Educación y Tecnología. En las demás áreas examinadas (Administración, Agropecuaria, Derecho y Humanidades) mujeres y hombres muestran un rendimiento similar durante el semestre.

De manera distinta, al revisar el promedio de las notas obtenidas en el examen se observa que en cinco áreas las mujeres obtienen un rendimiento inferior al obtenido por los hombres, a saber: en Agropecuaria, Arte y Arquitectura, Educación, Humanidades y Tecnología. La diferencia más significativa se da en el área de Humanidades, en la que las mujeres tienen un rendimiento inferior en 0,4 puntos. No obstante, ellas obtienen mejores resultados en sus exámenes en las áreas de Ciencias Sociales y Derecho, aunque sea sólo una décima de punto.

Cabe observar que las diferencias existentes entre las notas de presentación y las obtenidas en el primer examen son siempre negativas, lo que afecta a ambos géneros y a todas las áreas disciplinarias de las carreras evaluadas. No obstante lo cual, con excepción de las áreas de Derecho y Administración, las diferencias que muestran las mujeres son mayores a las que se observan en los hombres.

Al respecto, cabe señalar que, en todo caso, la diferencia entre ambos géneros no es significativa, con excepción de las áreas de Arte y Arquitectura y Humanidades, donde la diferencia entre las notas de presentación y las del primer examen son superiores en los hombres en 0,5 y 0,4 puntos, respectivamente. 
d) Notas de presentación y de primer examen por género y tipo de asignatura ${ }^{4}$.

Tabla $\mathrm{N}^{\mathrm{o}} 4$

\begin{tabular}{|l|l|c|c|}
\hline Tipo asignatura & Datos & Femenino & Masculino \\
\hline Administración & Promedio de N.P. & 4,4 & 4,7 \\
& Promedio de N.E.1 & 3,9 & 3,9 \\
\hline \multirow{2}{*}{ Auditoría y Contabilidad } & Promedio de N.P. & 4,8 & 4,7 \\
& Promedio de N.E.1 & 3,3 & 3,4 \\
\hline Ciencias Básicas & Promedio de N.P. & 4,5 & 4,4 \\
& Promedio de N.E.1 & 3,2 & 2,9 \\
\hline Ciencias Sociales & Promedio de N.P. & 5,1 & 5,0 \\
& Promedio de N.E.1 & 3,9 & 4,2 \\
\hline Computación & Promedio de N.P. & 5,1 & 5,1 \\
& Promedio de N.E.1 & 2,8 & 3,0 \\
\hline Derecho & Promedio de N.P. & 4,5 & 4,5 \\
& Promedio de N.E.1 & 3,8 & 3,7 \\
\hline Economía & Promedio de N.P. & 4,7 & 4,5 \\
& Promedio de N.E.1 & 3,6 & 3,4 \\
\hline Educación & Promedio de N.P. & 5,3 & 5,0 \\
& Promedio de N.E.1 & 4,2 & 4,3 \\
\hline Humanidades & Promedio de N.P. & 5,8 & 5,2 \\
& Promedio de N.E.1 & 5,1 & 4,9 \\
\hline Letras & Promedio de N.P. & 5,3 & 4,9 \\
& Promedio de N.E.1 & 4,2 & 4,1 \\
\hline Matemáticas & Promedio de N.P. & 4,4 & 4,2 \\
& Promedio de N.E.1 & 2,4 & 2,5 \\
\hline Psicología & Promedio de N.P. & 5,1 & 4,7 \\
& Promedio de N.E.1 & 3,9 & 4,0 \\
\hline Total Promedio de N.P. & & 5,0 & 4,6 \\
\hline Total Promedio de N.E.1 & & 3,8 & 3,4 \\
\hline
\end{tabular}

Al agrupar el rendimiento académico de los alumnos por tipo de asignatura evaluada, se observa que en nueve de las doce áreas establecidas las mujeres mostraron un rendimiento semestral superior al de los hombres. La diferencia más significativa se observa en las asignaturas pertenecientes al área de Humanidades, donde las mujeres superan por 6 décimas de punto a los hombres. En otras dos categorías

4 El universo analizado bajo la variable "tipo de asignatura" no corresponde al 100\% de las asignaturas examinadas, por cuanto algunas no eran clasificables en ninguna de las categorías definidas, razón por la cual su asignación de categoría es vacía. 
el rendimiento es similar y sólo en una de ellas, Administración, los hombres obtienen un promedio de notas de presentación a examen que es superior.

Con relación a las notas obtenidas en el examen, llama la atención que la hegemonía mostrada por las mujeres en el análisis de la variable anterior se diluye, y sólo en cinco de las doce categorías establecidas las alumnas obtuvieron un resultado superior al de los hombres en los exámenes aplicados. En cambio, éstos obtuvieron un mejor rendimiento en seis categorías distintas, destacándose el área de Ciencias Sociales, donde el promedio les favorece por 3 décimas de punto. Sólo en una categoría, Administración, las notas de los exámenes entre ambos géneros son similares.

En términos generales, se puede señalar que ambos géneros obtuvieron sus mejores resultados en los exámenes aplicados a aquellas asignaturas que pertenecen al área de Humanidades. Las notas más bajas, por su parte, se observan en las asignaturas que pertenecen al área de Matemáticas.

En relación con la diferencia entre el promedio de las notas de presentación y las notas obtenidas en el examen, en las asignaturas del área de Computación se advierte una diferencia muy superior a las demás áreas, observándose que hombres y mujeres tienen un comportamiento más o menos similar, pues las primeras obtienen una diferencia de 2,3 puntos, mientras que en los hombres esta diferencia es de 2,1 puntos. La diferencia menor se observa, en el caso de las mujeres, en las asignaturas del área de Administración, donde la diferencia entre ambos promedios es de cinco décimas de punto. Los hombres en cambio, mostraron un rendimiento más uniforme en las asignaturas del área de Humanidades, donde la diferencia fue de apenas 3 décimas de punto. En esta misma área las mujeres mostraron una diferencia de 7 décimas de punto. 
e) Notas de presentación y de primer examen, por tipo de institución y de asignatura

Tabla $\mathrm{N}^{\circ} 5$

\begin{tabular}{|l|l|l|cc|}
\hline Tipo Institución & Tipo asignatura & Datos & Femenino & Masculino \\
\hline \multirow{4}{*}{} & Administración & Promedio de N.P. & 5,3 & 5,3 \\
& & Promedio de N.E.1 & 3,6 & 4,0 \\
\cline { 2 - 5 } & Auditoría y Contabilidad & Promedio de N.P. & 5,0 & 4,9 \\
& & Promedio de N.E.1 & 3,2 & 3,4 \\
\cline { 2 - 5 } & Ciencias Básicas & Promedio de N.P. & 4,5 & 4,5 \\
& & Promedio de N.E.1 & 2,4 & 2,1 \\
\cline { 2 - 5 } & Ciencias Sociales & Promedio de N.P. & 5,2 & 4,7 \\
& & Promedio de N.E.1 & 4,8 & 4,1 \\
\cline { 2 - 5 } & Computación & Promedio de N.P. & 5,3 & 5,4 \\
& & Promedio de N.E.1 & 2,2 & 2,2 \\
\cline { 2 - 5 } & Derecho & Promedio de N.P. & 6,0 & 5,3 \\
& & Promedio de N.E.1 & 3,4 & 3,4 \\
\cline { 2 - 5 } & Economía & Promedio de N.P. & 4,5 & 4,5 \\
& & Promedio de N.E.1 & 3,6 & 3,4 \\
\cline { 2 - 5 } & Educación & Promedio de N.P. & 5,4 & 4,5 \\
& & Promedio de N.E.1 & 4,5 & 4,3 \\
\cline { 2 - 5 } & Humanidades & Promedio de N.P. & 4,0 & 3,8 \\
& & Promedio de N.E.1 & 3,8 & 3,1 \\
\cline { 2 - 5 } & Letras & Promedio de N.P. & 5,4 & 5,1 \\
& & Promedio de N.E.1 & 4,4 & 4,5 \\
\cline { 2 - 5 } & Matemáticas & Promedio de N.P. & 4,6 & 4,6 \\
& & Promedio de N.E.1 & 2,1 & 2,4 \\
\cline { 2 - 5 } & Psicología & Promedio de N.P. & 5,8 & 4,7 \\
& & Promedio de N.E.1 & 4,6 & 4,8 \\
\hline
\end{tabular}

En los institutos profesionales las mujeres mostraron un mejor rendimiento semestral en las asignaturas pertenecientes a las áreas de Derecho y Psicología, donde obtuvieron promedios de presentación de 6,0 y 5,8, respectivamente. En ambos casos, su rendimiento fue significativamente superior al de los hombres, superándolos en 0,7 y 1,1 puntos. Por su parte, los hombres mostraron un mejor rendimiento en las asignaturas pertenecientes al área de Computación. Sin embargo, esta diferencia no fue significativa en relación con el rendimiento de las mujeres, y solamente consiguieron superarlas por una décima de punto.

En relación con las notas obtenidas en el examen, las alumnas de los institutos profesionales obtuvieron sus mejores resultados en las 
asignaturas de las áreas de Ciencias Sociales, Psicología y Educación. Los hombres, por su parte, obtuvieron sus mejores notas en los exámenes de las asignaturas pertenecientes a las áreas de Psicología y Letras. A diferencia de las notas promedio de presentación, donde las mujeres muestran un rendimiento que es igual o superior al de los hombres en casi todas las áreas, estos últimos mostraron obtener mejores resultados en las instancias de evaluación final, superando a las mujeres en cinco de las áreas evaluadas: Administración, Auditoría y Contabilidad, Letras, Matemáticas y Psicología. Las mujeres, en cambio, superan a los hombres en su rendimiento en el examen en las áreas de Ciencias Básicas, Ciencias Sociales, Economía, Educación y Humanidades. En las áreas restantes el rendimiento fue similar.

En todo caso, vale la pena destacar el bajo rendimiento de los alumnos de institutos profesionales en los exámenes de las asignaturas de las áreas de Ciencias Básicas, Computación y Matemáticas, donde ninguno de los promedios superó la nota 2,5. En estos tres casos hombres y mujeres obtuvieron resultados deficitarios. La comparación entre las notas obtenidas en el examen entre ambos géneros se observa en el siguiente gráfico:

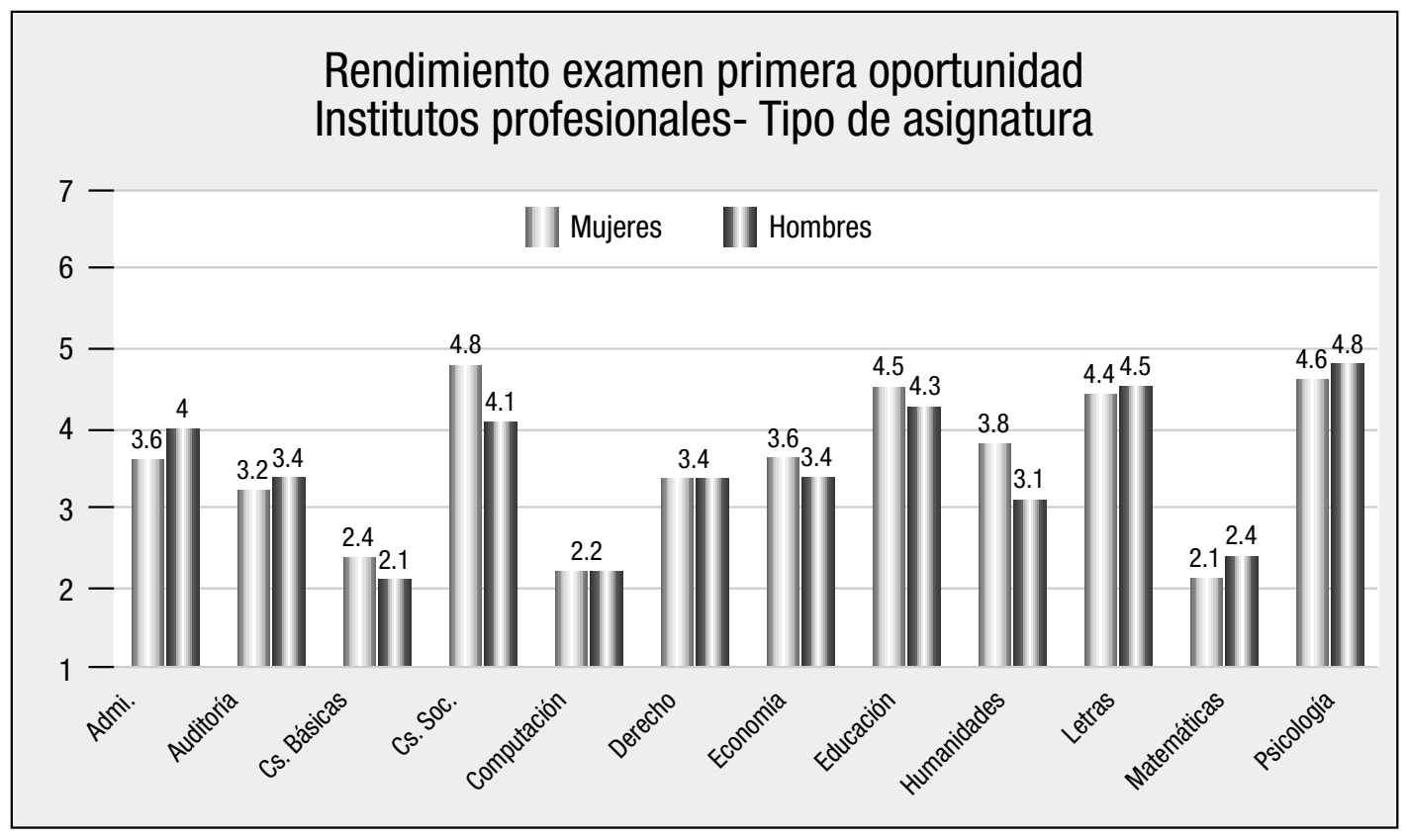


Tabla $\mathrm{N}^{\mathrm{o}} 6$

\begin{tabular}{|c|c|c|c|c|}
\hline Tipo Institución & Tipo asignatura & Datos & Femenino & Masculino \\
\hline \multirow{24}{*}{ Universidades } & \multirow[t]{2}{*}{ Administración } & Promedio de N.P. & 4,1 & 4,2 \\
\hline & & Promedio de N.E.1 & 3,9 & 3,9 \\
\hline & \multirow[t]{2}{*}{ Auditoría y Contabilidad } & Promedio de N.P. & 4,5 & 4,4 \\
\hline & & Promedio de N.E.1 & 3,5 & 3,4 \\
\hline & \multirow[t]{2}{*}{ Ciencias Básicas } & Promedio de N.P. & 4,5 & 4,4 \\
\hline & & Promedio de N.E.1 & 3,3 & 3,3 \\
\hline & \multirow{2}{*}{ Ciencias Sociales } & Promedio de N.P. & 5,0 & 5,1 \\
\hline & & Promedio de N.E.1 & 3,8 & 4,2 \\
\hline & \multirow{2}{*}{ Computación } & Promedio de N.P. & 5,0 & 4,8 \\
\hline & & Promedio de N.E.1 & 3,3 & 3,7 \\
\hline & \multirow[t]{2}{*}{ Derecho } & Promedio de N.P. & 4,5 & 4,4 \\
\hline & & Promedio de N.E.1 & 3,8 & 3,7 \\
\hline & \multirow[t]{2}{*}{ Economía } & Promedio de N.P. & 4,7 & 4,5 \\
\hline & & Promedio de N.E.1 & 3,6 & 3,4 \\
\hline & \multirow{2}{*}{ Educación } & Promedio de N.P. & 5,3 & 5,3 \\
\hline & & Promedio de N.E.1 & 4,2 & 4,2 \\
\hline & \multirow[t]{2}{*}{ Humanidades } & Promedio de N.P. & 5,8 & 5,4 \\
\hline & & Promedio de N.E.1 & 5,1 & 5,1 \\
\hline & \multirow[t]{2}{*}{ Letras } & Promedio de N.P. & 4,7 & 4,7 \\
\hline & & Promedio de N.E.1 & 3,2 & 3,7 \\
\hline & \multirow[t]{2}{*}{ Matemáticas } & Promedio de N.P. & 4,3 & 3,8 \\
\hline & & Promedio de N.E.1 & 2,6 & 2,5 \\
\hline & \multirow[t]{2}{*}{ Psicología } & Promedio de N.P. & 5,0 & 4,7 \\
\hline & & Promedio de N.E.1 & 3,9 & 3,9 \\
\hline
\end{tabular}

En el caso de los alumnos que siguen estudios en universidades y que fueron examinados por el Consejo Superior de Educación se puede observar que las mujeres muestran un rendimiento semestral que es, en la mayoría de los casos, superior al de los hombres, superándolos hasta en 5 décimas de punto. No obstante, la diferencia no es tan significativa como la observada en algunas de las áreas evaluadas en institutos profesionales. Los hombres obtienen un mejor rendimiento semestral solamente en dos áreas: Administración y Ciencias Sociales. No obstante, la diferencia es de apenas una décima de punto.

Por otra parte, el rendimiento observado en el examen también es bastante similar entre hombres y mujeres, sin que se observen grandes diferencias entre unos y otros. Las diferencias más significativas están en las áreas de Letras, Ciencias Sociales y Computación, donde los hombres mostraron un rendimiento superior en cinco décimas para el primer caso y cuatro para el segundo y tercero. 
Además, la diferencia entre las notas de presentación a examen y las notas allí obtenidas es relativamente similar entre mujeres y hombres. Solamente resultan ser una excepción los casos de las asignaturas de las áreas de Computación y Letras, en las que los hombres mostraron diferencias de 1,1 y 1 punto, mientras que las mujeres tienen una diferencia de 1,7 y 1,5 en cada caso.

El rendimiento de mujeres y hombres en las universidades en el examen de primera oportunidad se puede observar en el siguiente gráfico:

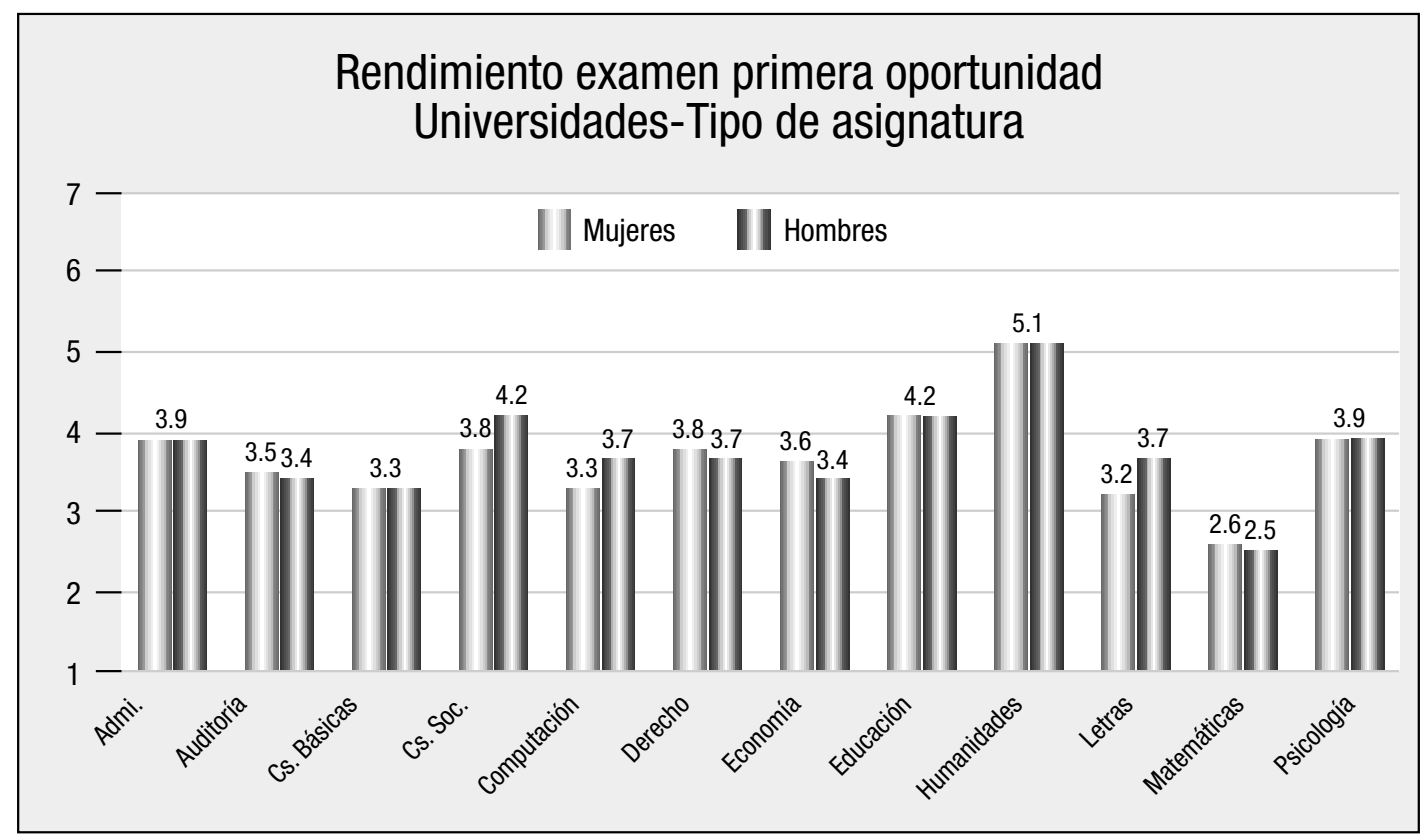

A modo de conclusión, se puede señalar que los alumnos pertenecientes a universidades muestran un rendimiento particularmente deficiente en las asignaturas del área de Matemáticas, en la que mujeres y hombres obtuvieron un promedio de notas de examen de 2,6 y 2,5 puntos, respectivamente. 
f) Notas de presentación y de primer examen, por tipo de institución y área temática de la carrera.

Tabla $\mathrm{N}^{\circ} 7$

\begin{tabular}{|c|c|c|c|c|}
\hline Tipo Institución & Área & Datos & Femenino & Masculino \\
\hline \multirow{12}{*}{$\begin{array}{l}\text { Institutos } \\
\text { Profesionales }\end{array}$} & \multirow[t]{2}{*}{ Administración } & Promedio de N.P. & 4,9 & 4,8 \\
\hline & & Promedio de N.E.1 & 2,9 & 3,0 \\
\hline & \multirow[t]{2}{*}{ Arte y Arquitectura } & Promedio de N.P. & 5,0 & 4,7 \\
\hline & & Promedio de N.E.1 & 3,8 & 4,0 \\
\hline & \multirow[t]{2}{*}{ Ciencias Sociales } & Promedio de N.P. & 5,8 & 5,5 \\
\hline & & Promedio de N.E.1 & 4,7 & 4,4 \\
\hline & \multirow{2}{*}{ Educación } & Promedio de N.P. & 5,5 & 5,0 \\
\hline & & Promedio de N.E.1 & 4,7 & 4,2 \\
\hline & \multirow[t]{2}{*}{ Humanidades } & Promedio de N.P. & 5,4 & 5,1 \\
\hline & & Promedio de N.E.1 & 4,4 & 4,5 \\
\hline & \multirow[t]{2}{*}{ Tecnología } & Promedio de N.P. & 4,7 & 4,9 \\
\hline & & Promedio de N.E.1 & 2,7 & 2,7 \\
\hline
\end{tabular}

Al analizar el rendimiento académico de los alumnos de los institutos profesionales, según las áreas temáticas de las carreras impartidas, se puede concluir que las mujeres obtienen mejores notas promedio de presentación en cinco de las seis áreas examinadas, observándose las notas más altas en las carreras de las áreas de Ciencias Sociales y Educación. Los alumnos hombres de institutos profesionales sólo obtienen un mejor rendimiento semestral en las carreras pertenecientes al área de Tecnología.

Por el contrario, esta diferencia se acorta al analizar el rendimiento en los exámenes aplicados por el Consejo, donde las alumnas mujeres obtienen mejores resultados sólo en dos de las seis áreas examinadas: Ciencias Sociales y Educación. Los hombres, por su parte, obtienen mejores resultados en tres de las áreas examinadas, y sólo en un área, Tecnología, los rendimientos en los exámenes fueron similares entre ambos géneros.

La diferencia más significativa entre las notas promedio de presentación a examen y las notas obtenidas en él, se da en el caso de las carreras del área de Tecnología, donde mujeres y hombres muestran una diferencia de 2 y 2,2 puntos, respectivamente. 


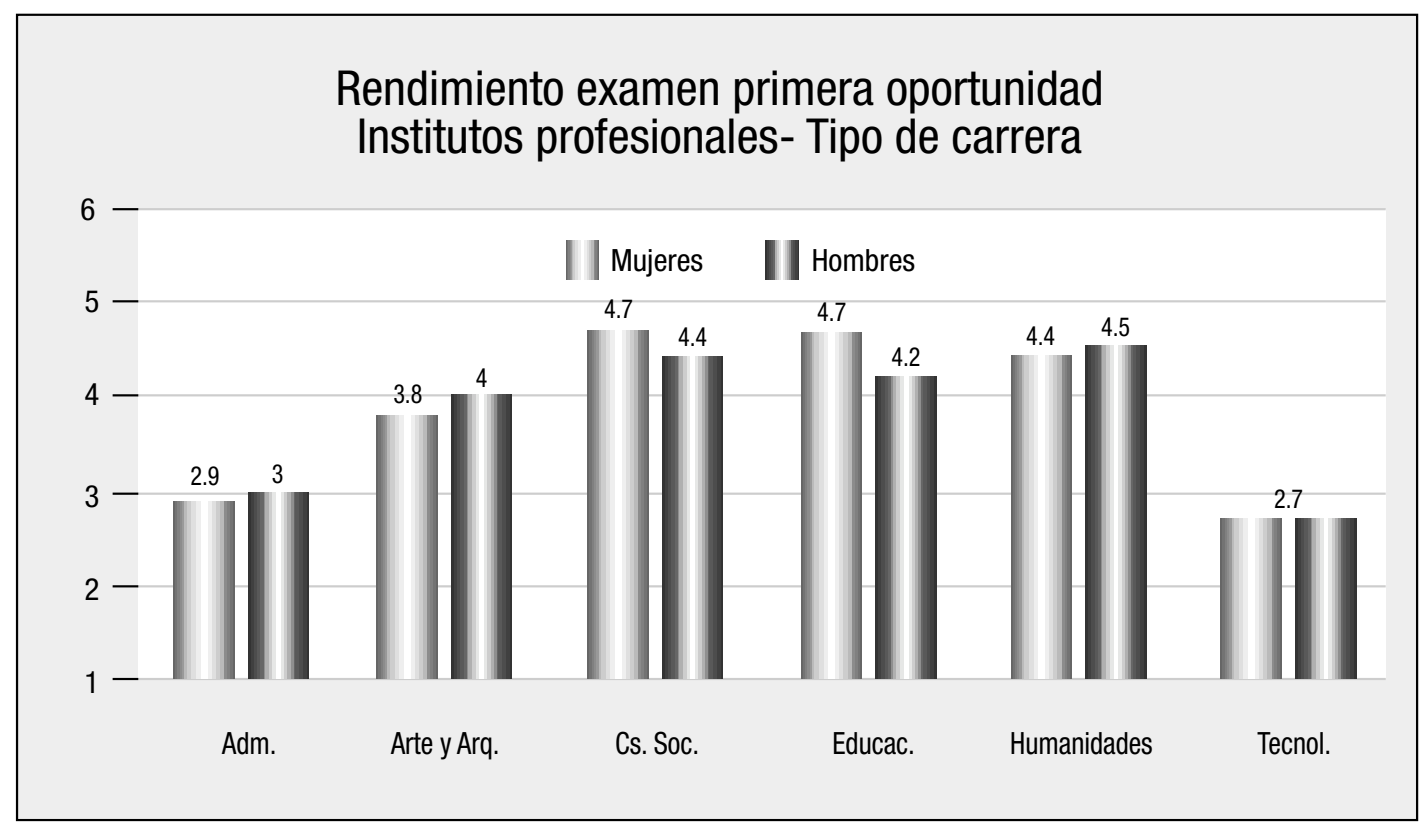

Para el caso de las universidades, los datos son los siguientes:

Tabla $\mathrm{N}^{\circ} 8$

\begin{tabular}{|c|c|c|c|c|}
\hline Tipo Institución & Área & Datos & Femenino & Masculino \\
\hline \multirow{14}{*}{ Universidades } & \multirow{2}{*}{ Administración } & Promedio de N.P. & 4,5 & 4,4 \\
\hline & & Promedio de N.E.1 & 3,4 & 3,4 \\
\hline & \multirow[t]{2}{*}{ Agropecuaria } & Promedio de N.P. & 4,7 & 4,7 \\
\hline & & Promedio de N.E.1 & 3,1 & 3,2 \\
\hline & \multirow[t]{2}{*}{ Ciencias Sociales } & Promedio de N.P. & 4,9 & 4,7 \\
\hline & & Promedio de N.E.1 & 3,8 & 3,8 \\
\hline & \multirow[t]{2}{*}{ Derecho } & Promedio de N.P. & 4,5 & 4,5 \\
\hline & & Promedio de N.E.1 & 3,8 & 3,7 \\
\hline & \multirow[t]{2}{*}{ Educación } & Promedio de N.P. & 5,4 & 5,2 \\
\hline & & Promedio de N.E.1 & 4,0 & 3,9 \\
\hline & \multirow[t]{2}{*}{ Humanidades } & Promedio de N.P. & 4,7 & 5,3 \\
\hline & & Promedio de N.E.1 & 4,9 & 5,1 \\
\hline & \multirow[t]{2}{*}{ Tecnología } & Promedio de N.P. & 4,3 & 3,8 \\
\hline & & Promedio de N.E.1 & 3,0 & 3,0 \\
\hline
\end{tabular}

En el caso de las universidades, las mujeres obtienen mejores notas promedio de presentación que los hombres en cuatro de los siete tipos de carrera evaluadas, diferencia que se expresa en puntajes que van desde los 0,1 hasta los 0,5 puntos. Los hombres, por su parte, sólo obtienen una nota de presentación más alta en un área: Humanidades, donde se aprecia una diferencia entre ambos géneros de 0,6 puntos. Los promedios más altos se obtuvieron en las áreas de Educación y Ciencias Sociales, en el caso de las mujeres, y de Humanidades y Educación, en el de los hombres. 
En relación con las notas obtenidas en el examen, las alumnas pertenecientes a carreras de las áreas de Humanidades y Educación obtuvieron las notas más altas, en relación con las demás áreas disciplinarias. Al comparar sus resultados con los alumnos hombres no se advierten grandes diferencias, y en tres áreas los promedios de las notas de examen son similares entre ambos géneros. En las demás áreas las diferencias favorecen a mujeres y hombres, pero sólo por una décima de punto.

Finalmente, se puede señalar que en el área de Humanidades las mujeres mostraron un mejor rendimiento en sus exámenes que en las evaluaciones del semestre, lo que resulta particularmente llamativo porque es el único caso en que ello sucede.

Las mayores diferencias entre estos indicadores estuvieron dadas en las carreras del área de Agropecuaria, donde se observan, para mujeres y hombres, diferencias de 1,6 y 1,5 puntos.

El rendimiento en el examen aplicado por el Consejo puede apreciarse en el siguiente gráfico:

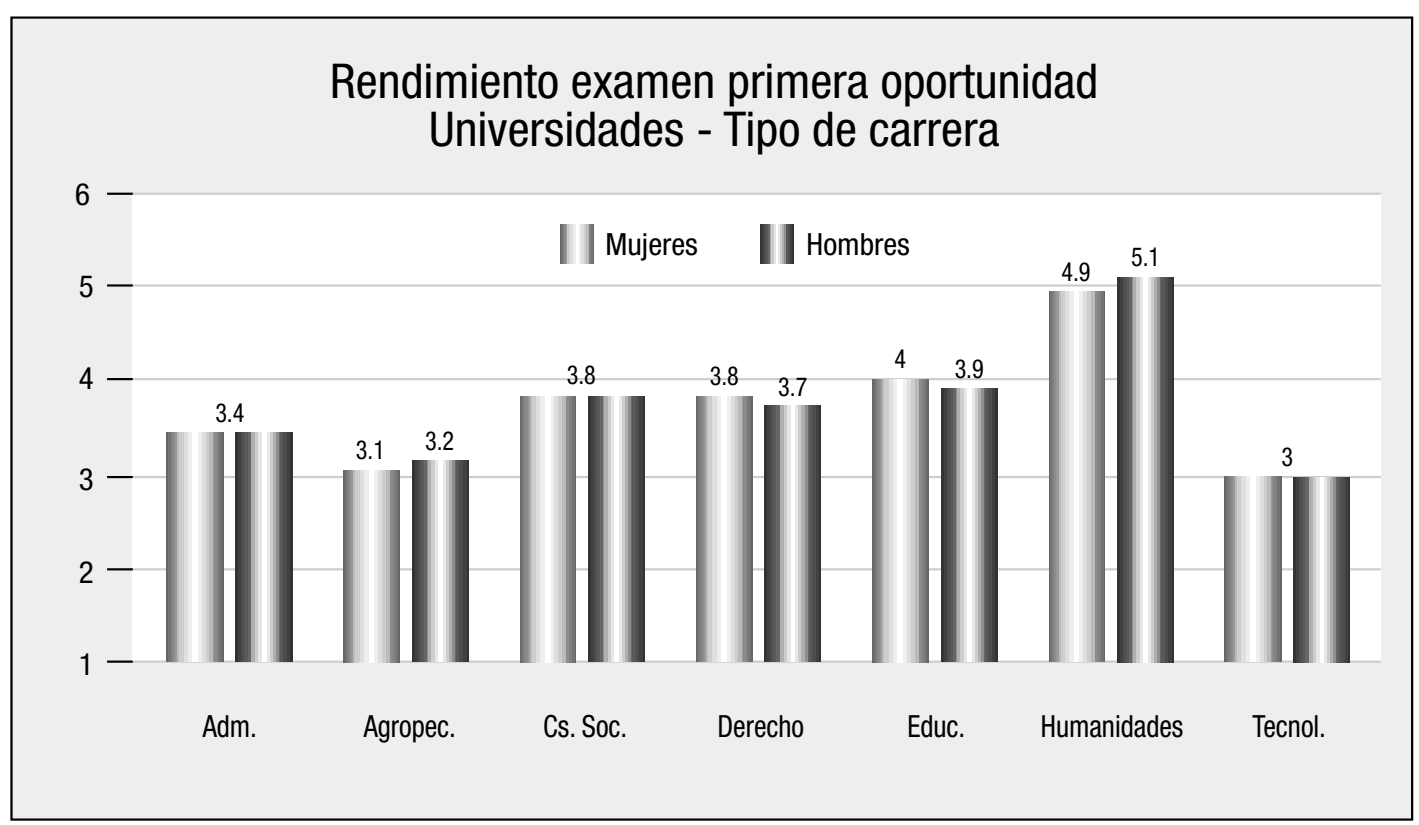

g) Correlación existente entre las notas de presentación y las notas del primer examen, por género y tipo de institución.

En términos generales, es posible afirmar que las mujeres muestran un mayor grado de correlación entre sus notas de 
presentación y las notas obtenidas en el primer examen, que, aunque leve, es digno de destacar en una distribución de más de 10.000 casos. Las mujeres obtienen una correlación de 0,33 (r de Pearson ${ }^{5}$ ) frente a un 0,31 del mismo indicador para los hombres.

No obstante los similares niveles de correlación observados, al agregar al análisis el tipo de institución en que estudian los alumnos esta similitud se rompe, pues las mujeres en los institutos profesionales presentan una correlación de 0,39 entre sus notas de presentación y la notas del primer examen, mientras que los hombres sólo un 0,23.

$\mathrm{Al}$ analizar la correlación entre ambas notas en las universidades, se obtiene un resultado contrario, pues en este tipo de instituciones las mujeres presentan una correlación de 0,33 , la que resulta inferior a la correlación que muestran los hombres $(0,41)$.

Por otra parte, si se incorpora la variable "jornada" se observa que las alumnas que asisten a clases en jornada vespertina presentan un nivel de correlación de 0,32, el que resulta muy similar al que presentan los hombres, que es de 0,33 . En cambio, en la jornada diurna las mujeres presentan una correlación notoriamente mayor: 0,34 frente a 0,29 de los hombres.

h) Porcentaje de aprobación del primer examen, por tipo de institución y jornada

Tabla $\mathrm{N}^{\circ} 9$

\begin{tabular}{|l|c|c|c|}
\hline Tipo Institución & Jornada & Sexo & Aprueba $1^{\circ}$ \\
\hline \multirow{4}{*}{ Institutos Profesionales } & Diurna & Femenino & $40,3 \%$ \\
& & Masculino & $30,8 \%$ \\
\cline { 2 - 4 } & Vespertina & Femenino & $30,4 \%$ \\
& & Masculino & $31,6 \%$ \\
\hline \multirow{3}{*}{ Universidades } & Diurna & Femenino & $49,9 \%$ \\
& & Masculino & $39,9 \%$ \\
\cline { 2 - 4 } & Vespertina & Femenino & $37,9 \%$ \\
& & Masculino & $39,2 \%$ \\
\hline Total general & & & $41,3 \%$ \\
\hline
\end{tabular}

5 El coeficiente de relación de Pearson es una prueba estadística que permite analizar la relación entre dos variables medidas en un nivel por intervalos o de razón. Considera a ambas variables como independientes, es decir, sin establecer ninguna relación de causalidad entre ellas. Puede variar de $-1,00 \mathrm{a}+1,00$, representando un extremo la correlación negativa perfecta y la otra la positiva. Por ejemplo, el resultado $+0,10$ indica una correlación positiva débil, mientras que el 0,50 indica una correlación positiva media. 
Al analizar el porcentaje de aprobación del primer examen, descompuesto por género y tipo de institución, se aprecian algunas diferencias entre ambos géneros que resultan significativas. En efecto, se puede observar que las alumnas que estudian en institutos profesionales obtienen una diferencia sobre sus compañeros hombres que es superior en 5 puntos porcentuales. Ésta se hace aún más significativa en el caso de las universidades, donde las mujeres obtienen una de 7,5 puntos porcentuales sobre los hombres.

$\mathrm{Si}$, además, se agrega al análisis la variable jornada, se puede concluir que en los institutos profesionales las alumnas que asisten en jornada diurna muestran un porcentaje de aprobación que es superior en casi diez puntos porcentuales, pues, mientras del total de mujeres que rinden el primer examen un 40,3\% lo aprueba, en el caso de los hombres este indicador sólo alcanza al 30,8\%. De manera distinta en el caso de la jornada vespertina de los institutos profesionales la diferencia existente entre los hombres y las mujeres, además de aminorarse en forma sustantiva, resulta favorable a los hombres por un $1,2 \%$

En el caso de las universidades que imparten actividades en jornada diurna, el porcentaje de mujeres que aprueba el primer examen alcanza casi el $50 \%$ del total de alumnas que lo rindieron, superando en diez puntos porcentuales el porcentaje de aprobación que muestran los hombres. Tal como sucede con los institutos profesionales, esta diferencia se revierte en el caso de la jornada vespertina, donde los rendimientos de ambos géneros son muy similares, favoreciendo a los hombres sólo por un 1,3\%. 
i) Porcentaje de aprobación del primer examen por área de carrera examinada

Tabla $\mathrm{N}^{\circ} 10$

\begin{tabular}{|c|c|c|}
\hline Área & Sexo & Aprueba $1^{\circ}$ \\
\hline Administración & Femenino & $30,7 \%$ \\
& Masculino & $30,5 \%$ \\
\hline \multirow{2}{*}{ Agropecuaria } & Femenino & $18,2 \%$ \\
& Masculino & $22,6 \%$ \\
\hline Arte y Arquitectura & Femenino & $47,1 \%$ \\
& Masculino & $55,9 \%$ \\
\hline Ciencias Sociales & Femenino & $50,3 \%$ \\
& Masculino & $46,4 \%$ \\
\hline Derecho & Femenino & $53,1 \%$ \\
& Masculino & $54,6 \%$ \\
\hline Educación & Femenino & $52,5 \%$ \\
& Masculino & $57,9 \%$ \\
\hline Humanidades & Femenino & $66,2 \%$ \\
& Masculino & $71,9 \%$ \\
\hline Tecnología & Femenino & $17,6 \%$ \\
& Masculino & $19,7 \%$ \\
\hline Total general & & $41,3 \%$ \\
\hline
\end{tabular}

Al analizar los porcentajes de aprobación de examen incorporando la variable "área de carrera" y cruzarla con el "rendimiento por género", se puede apreciar que en tres de las ocho áreas temáticas examinadas existen diferencias significativas entre el rendimiento de ambos géneros, las que superan los cinco puntos porcentuales. En estos tres casos la diferencia favorece a los hombres, y corresponden al área de Arte y Arquitectura, donde los hombres superan por 8,8\% el porcentaje de aprobación del primer examen que obtienen las mujeres; Educación, donde los hombres obtienen un porcentaje de aprobación de examen que es superior al de las mujeres en 5,4 puntos porcentuales; y Humanidades, donde el porcentaje de hombres que supera el primer examen es superior al de las mujeres en 5,7\%.

Las mujeres solamente obtuvieron resultados superiores a los hombres en las carreras del área de Ciencias Sociales, superando a éstos últimos en casi 4 puntos porcentuales.

Las diferencias de aprobación entre ambos géneros, según carreras evaluadas, se pueden apreciar en el siguiente gráfico: 


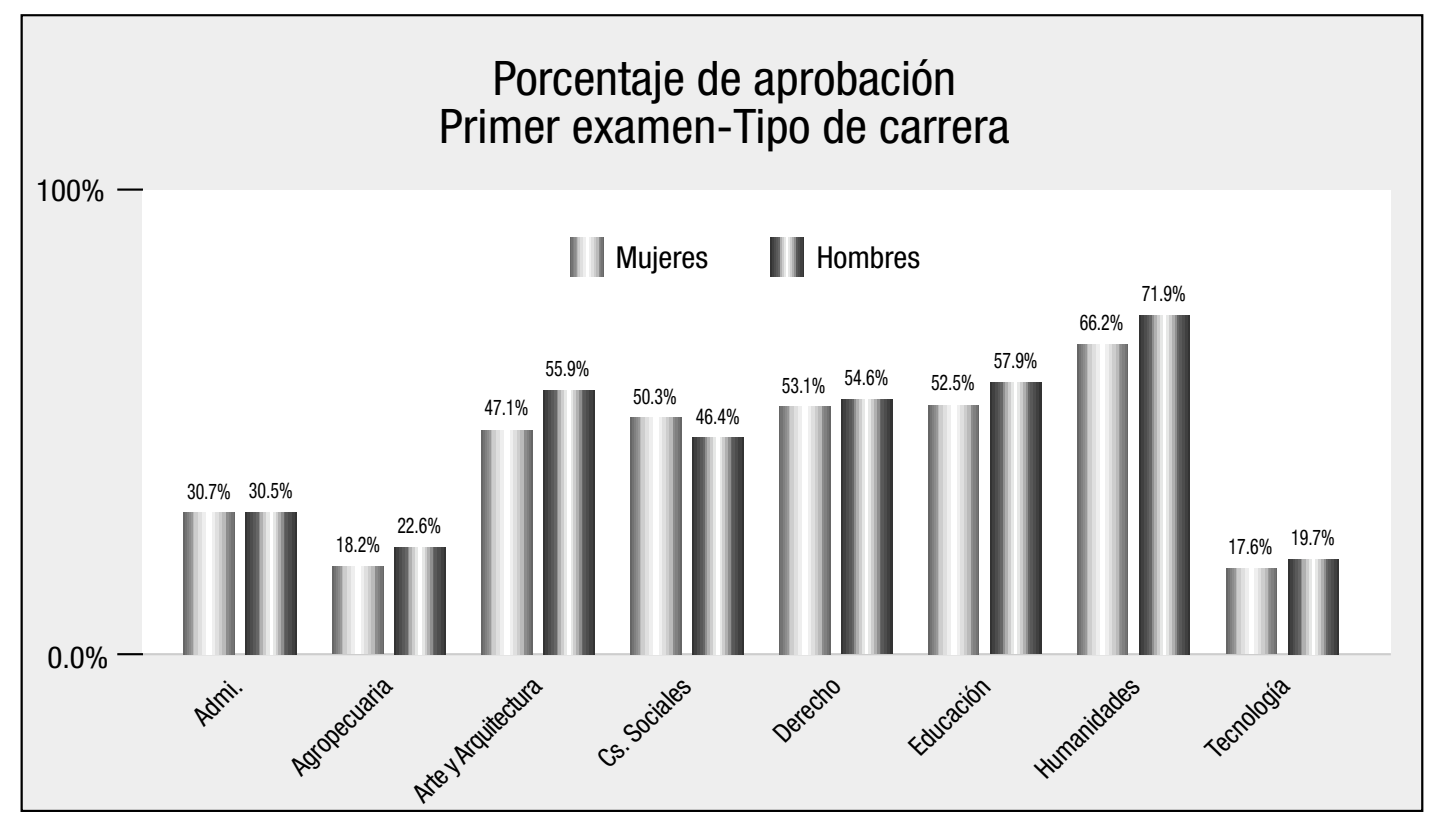

j) Porcentaje de aprobación del primer examen por tipo de asignatura Tabla $\mathrm{N}^{\circ} 11$

\begin{tabular}{|c|c|c|}
\hline Tipo asignatura & Sexo & Aprueba $1^{\circ}$ \\
\hline \multirow[t]{2}{*}{ Administración } & Femenino & $52,3 \%$ \\
\hline & Masculino & $52,7 \%$ \\
\hline \multirow[t]{2}{*}{ Auditoría y Contabilidad } & Femenino & $30,1 \%$ \\
\hline & Masculino & $33,0 \%$ \\
\hline \multirow{2}{*}{ Ciencias Básicas } & Femenino & $21,2 \%$ \\
\hline & Masculino & $18,2 \%$ \\
\hline \multirow[t]{2}{*}{ Ciencias Sociales } & Femenino & $47,2 \%$ \\
\hline & Masculino & $54,4 \%$ \\
\hline \multirow[t]{2}{*}{ Computación } & Femenino & $20,5 \%$ \\
\hline & Masculino & $26,3 \%$ \\
\hline \multirow[t]{2}{*}{ Derecho } & Femenino & $51,6 \%$ \\
\hline & Masculino & $53,3 \%$ \\
\hline \multirow[t]{2}{*}{ Economía } & Femenino & $33,9 \%$ \\
\hline & Masculino & $30,9 \%$ \\
\hline \multirow[t]{2}{*}{ Educación } & Femenino & $62,2 \%$ \\
\hline & Masculino & $68,8 \%$ \\
\hline \multirow[t]{2}{*}{ Humanidades } & Femenino & $90,6 \%$ \\
\hline & Masculino & $75,6 \%$ \\
\hline \multirow[t]{2}{*}{ Letras } & Femenino & $57,1 \%$ \\
\hline & Masculino & $55,3 \%$ \\
\hline \multirow[t]{2}{*}{ Matemáticas } & Femenino & $13,7 \%$ \\
\hline & Masculino & $13,4 \%$ \\
\hline \multirow[t]{2}{*}{ Psicología } & Femenino & $49,1 \%$ \\
\hline & Masculino & $53,6 \%$ \\
\hline Total general & & $41,6 \%$ \\
\hline
\end{tabular}


Al integrar la variable "tipo de asignatura" en el análisis de rendimiento en el primer examen por género, se observa que en 4 de los 12 tipos de asignaturas examinadas existen diferencias significativas (mayor o igual a los 5 puntos porcentuales) entre el rendimiento de uno y otro género. En las asignaturas de las áreas de Ciencias Sociales, Computación y Educación el porcentaje de hombres que aprueba el primer examen es significativamente superior al de aprobación obtenido por las mujeres, con valores de 7,2\%, 5,7\% y $6,6 \%$, respectivamente. Por su parte, en las asignaturas del área de Humanidades las mujeres obtuvieron porcentajes de aprobación de exámenes superior por 15 puntos porcentuales a los hombres.

Esto puede apreciarse en el siguiente gráfico:

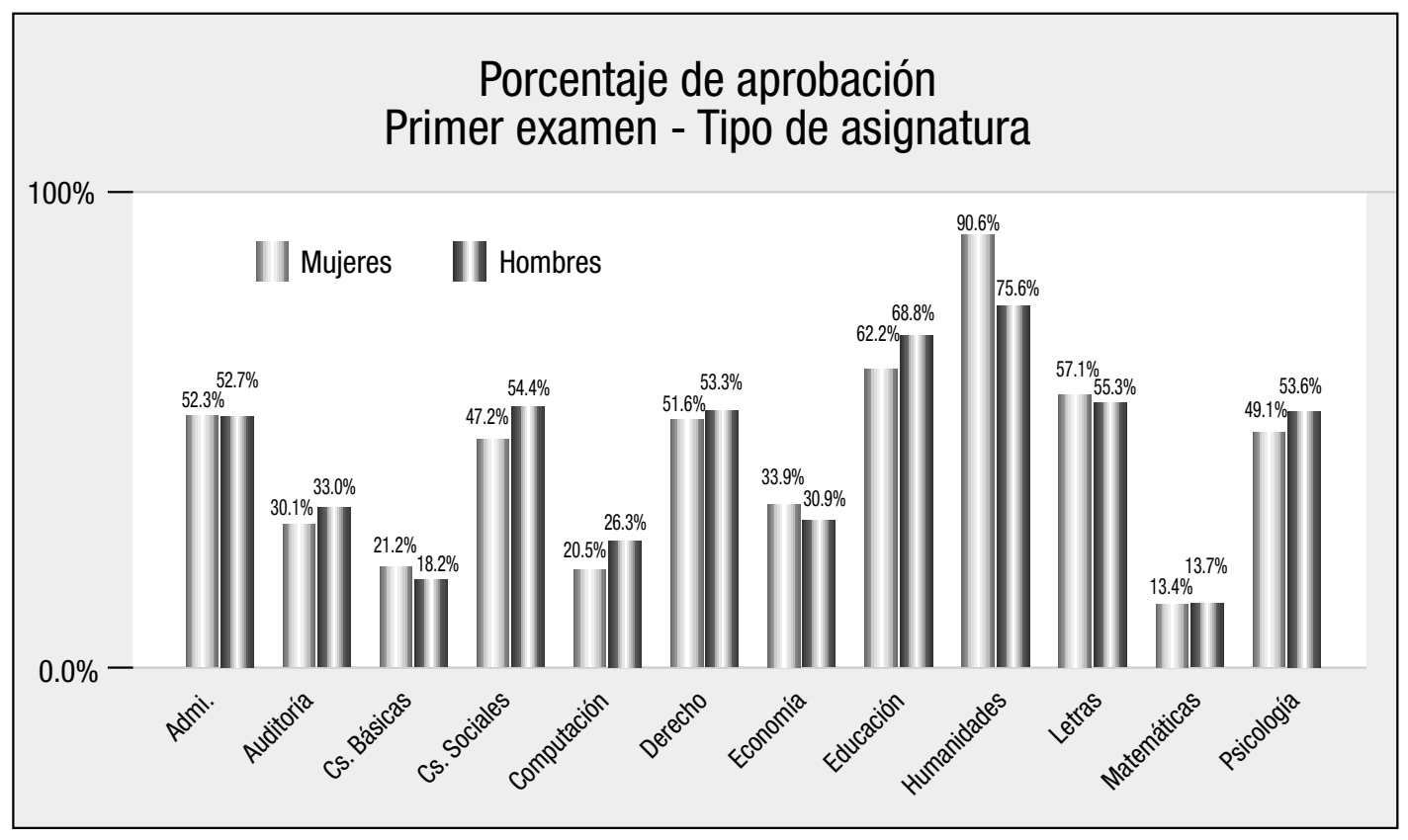


k) Porcentaje de aprobación del primer examen por tipo de institución y asignatura

Tabla $\mathrm{N}^{\circ} 12$

\begin{tabular}{|c|c|c|c|}
\hline Tipo Institución & Tipo asignatura & Sexo & Aprueba $1^{\circ}$ \\
\hline \multirow{24}{*}{$\begin{array}{l}\text { Institutos } \\
\text { Profesionales }\end{array}$} & \multirow[t]{2}{*}{ Administración } & Femenino & $42,6 \%$ \\
\hline & & Masculino & $54,3 \%$ \\
\hline & \multirow[t]{2}{*}{ Auditoría y Contabilidad } & Femenino & $26,2 \%$ \\
\hline & & Masculino & $32,1 \%$ \\
\hline & \multirow[t]{2}{*}{ Ciencias Básicas } & Femenino & $4,3 \%$ \\
\hline & & Masculino & $4,9 \%$ \\
\hline & \multirow[t]{2}{*}{ Ciencias Sociales } & Femenino & $74,2 \%$ \\
\hline & & Masculino & $52,8 \%$ \\
\hline & \multirow[t]{2}{*}{ Computación } & Femenino & $7,7 \%$ \\
\hline & & Masculino & $11,5 \%$ \\
\hline & \multirow[t]{2}{*}{ Derecho } & Femenino & $33,3 \%$ \\
\hline & & Masculino & $30,8 \%$ \\
\hline & \multirow[t]{2}{*}{ Economía } & Femenino & $30,1 \%$ \\
\hline & & Masculino & $22,6 \%$ \\
\hline & \multirow[t]{2}{*}{ Educación } & Femenino & $72,7 \%$ \\
\hline & & Masculino & $76,1 \%$ \\
\hline & \multirow{2}{*}{ Humanidades } & Femenino & $0,0 \%$ \\
\hline & & Masculino & $14,3 \%$ \\
\hline & \multirow[t]{2}{*}{ Letras } & Femenino & $63,6 \%$ \\
\hline & & Masculino & $65,0 \%$ \\
\hline & \multirow[t]{2}{*}{ Matemáticas } & Femenino & $9,5 \%$ \\
\hline & & Masculino & $12,6 \%$ \\
\hline & \multirow[t]{2}{*}{ Psicología } & Femenino & $72,5 \%$ \\
\hline & & Masculino & $91,0 \%$ \\
\hline
\end{tabular}

Como resultado de la revisión de los porcentajes de aprobación de examen que se observan en los institutos profesionales, descompuestos según el tipo de asignatura evaluada, se puede concluir que las mujeres obtuvieron mejores resultados en sólo 3 de las 12 áreas examinadas, mientras que los hombres los obtuvieron en las 9 áreas restantes. Llama la atención, en todo caso, la significativa diferencia que existe entre los porcentajes de aprobación de examen de las asignaturas pertenecientes a las áreas de Ciencias Sociales y Psicología. En la primera de ellas, las mujeres obtuvieron mejores resultados que los hombres, lo que se expresa en una diferencia de casi 22 puntos porcentuales. En la segunda, fueron los hombres los que obtuvieron mejores resultados, pero con una diferencia un poco menor: 19 puntos porcentuales. 
Además, se puede señalar que, en seis de los 12 tipos de asignaturas evaluadas, existen diferencias importantes entre el rendimiento de ambos géneros y que superan los 5 puntos porcentuales. De éstas, cuatro favorecen a los hombres -Administración, Auditoría y Contabilidad; Humanidades y Psicología con $11,7 \%, 5,9 \%, 14,3 \%$ y $18,5 \%$, respectivamente- y dos a las mujeres -Ciencias Sociales y Económicas, con 21,4\%, y 7,6\%, respectivamente.

Tabla $\mathrm{N}^{\circ} 13$

\begin{tabular}{|c|c|c|c|}
\hline Tipo Institución & Tipo asignatura & Sexo & Aprueba $1^{\circ}$ \\
\hline \multirow{12}{*}{ Universidades } & Administración & $\begin{array}{l}\text { Femenino } \\
\text { Masculino }\end{array}$ & $\begin{array}{l}55,6 \% \\
51,4 \%\end{array}$ \\
\hline & Auditoría y Contabilidad & $\begin{array}{l}\text { Femenino } \\
\text { Masculino }\end{array}$ & $\begin{array}{l}35,5 \% \\
34,6 \%\end{array}$ \\
\hline & Ciencias Básicas & $\begin{array}{l}\text { Femenino } \\
\text { Masculino }\end{array}$ & $\begin{array}{l}24,3 \% \\
25,2 \%\end{array}$ \\
\hline & Ciencias Sociales & $\begin{array}{l}\text { Femenino } \\
\text { Masculino }\end{array}$ & $\begin{array}{l}44,7 \% \\
54,6 \%\end{array}$ \\
\hline & Computación & $\begin{array}{l}\text { Femenino } \\
\text { Masculino }\end{array}$ & $\begin{array}{l}33,3 \% \\
39,5 \%\end{array}$ \\
\hline & Derecho & $\begin{array}{l}\text { Femenino } \\
\text { Masculino }\end{array}$ & $\begin{array}{l}52,2 \% \\
54,2 \%\end{array}$ \\
\hline & Economía & $\begin{array}{l}\text { Femenino } \\
\text { Masculino }\end{array}$ & $\begin{array}{l}35,3 \% \\
34,0 \% \\
\end{array}$ \\
\hline & Educación & $\begin{array}{l}\text { Femenino } \\
\text { Masculino }\end{array}$ & $\begin{array}{l}62,0 \% \\
64,3 \%\end{array}$ \\
\hline & Humanidades & $\begin{array}{l}\text { Femenino } \\
\text { Masculino }\end{array}$ & $\begin{array}{l}91,0 \% \\
81,3 \%\end{array}$ \\
\hline & Letras & $\begin{array}{l}\text { Femenino } \\
\text { Masculino }\end{array}$ & $\begin{array}{l}15,8 \% \\
44,4 \%\end{array}$ \\
\hline & Matemáticas & $\begin{array}{l}\text { Femenino } \\
\text { Masculino }\end{array}$ & $\begin{array}{l}17,2 \% \\
14,2 \%\end{array}$ \\
\hline & Psicología & $\begin{array}{l}\text { Femenino } \\
\text { Masculino }\end{array}$ & $\begin{array}{l}47,6 \% \\
46,4 \%\end{array}$ \\
\hline
\end{tabular}

En este caso, sólo hay cuatro áreas donde se observan diferencias significativas entre los porcentajes de aprobación de examen de mujeres y hombres, de las cuales una favorece a las mujeres -Humanidades, con $9,7 \%-$ y tres a los hombres -Ciencias Sociales, Computación y Letras, con $10 \%, 6,1 \%$ y $28,7 \%$, respectivamente.

En todo caso, llama la atención el bajo porcentaje de aprobación de examen que se observa en las asignaturas del área de Matemáticas, donde ni hombres ni mujeres superaron el 20\% de aprobación, sin 
perjuicio de que las primeras obtuvieron un porcentaje de aprobación superior en 3 puntos a los hombres. En contraposición, en el área de Humanidades ambos géneros obtuvieron porcentajes de aprobación que se consideran como altos, a pesar de que las mujeres, nuevamente, obtuvieron un rendimiento superior equivalente a casi diez puntos porcentuales.

\section{Conclusiones}

Se puede señalar que, en términos generales, las mujeres examinadas por el Consejo Superior de Educación mostraron un rendimiento académico superior al de los hombres, lo que se ve reflejado tanto en las notas de presentación a examen como en las allí obtenidas. Además, las mujeres obtuvieron mejores porcentajes de aprobación de examen, lo que da cuenta de un rendimiento más o menos coherente a lo largo del semestre.

No obstante lo anterior, es posible señalar que esta diferencia no siempre se observa al descomponer el análisis por las variables empleadas (tipo de institución, de jornada o clasificación de carreras y asignaturas examinadas), pues en varias de ellas los hombres mostraron un nivel de rendimiento superior al de sus compañeras.

En efecto, si bien las alumnas matriculadas en institutos profesionales tienen un rendimiento superior al de sus compañeros hombres, en las universidades esta diferencia es más bien menor, incluso en la jornada vespertina los hombres superan a las mujeres por un margen mínimo.

Por otra parte, se puede señalar que las mujeres obtuvieron mejores resultados que los hombres en la jornada diurna que en la vespertina, situación que se observa tanto en el caso de las universidades como en de los institutos profesionales.

Además, al analizar los resultados se pudo observar que, si bien las mujeres obtienen resultados superiores a los hombres en las evaluaciones realizadas durante el semestre y en los exámenes finales, los hombres mejoran relativamente su rendimiento en éstos, acortando las diferencias que se observan en las notas promedio de presentación. 
Por lo tanto, si se toma la hipótesis planteada al comienzo del estudio, se tiene que, efectivamente, existe una diferencia entre el rendimiento académico de ambos géneros, que indica que las mujeres obtienen resultados académicos superiores al de los hombres. Sin embargo, no se puede demostrar que se trate de una diferencia significativa, pues las diferencias observadas en la mayoría de los casos son menores y no dan cuenta de una superioridad absoluta y radical.

Con todo, llama la atención, al presentar las conclusiones de este estudio, la existencia de dos fenómenos que son comunes a ambos géneros, y que dan cuenta de situaciones que deberían generar preocupación al interior de las instituciones que imparten enseñanza de nivel superior, a saber:

La significativa diferencia que se observa entre el promedio de las notas de presentación a examen y el promedio de las notas obtenidas en él, lo que podría ser indicador de distintos fenómenos, como un bajo nivel de exigencia de las evaluaciones aplicadas durante el semestre, una falta de preparación de parte de los alumnos para rendir los exámenes aplicados por el Consejo o una disminución del rendimiento académico ante la presión que supone rendir un examen frente a un evaluador externo, lo que afecta casi por igual a alumnos de ambos géneros. Es esperable que ambas notas muestren cierta similitud y relación, pues dan cuenta del nivel de aprendizaje logrado tras un período académico.

El segundo fenómeno que llama la atención, es que alumnos de ambos géneros obtuvieron resultados deficitarios en las áreas de Matemáticas y Computación, donde tanto las notas de presentación como las obtenidas en los exámenes fueron significativamente inferiores a la nota mínima de aprobación. En contraposición a ello están las áreas de Humanidades y Ciencias Sociales, donde se observan los resultados más altos en ambos géneros, y los porcentajes de aprobación de los exámenes finales son considerablemente altos en comparación con el promedio observado en las demás áreas.

Si bien estos fenómenos no son el objeto de este estudio, lo que impide contar con antecedentes para formular juicios conclusivos sobre ellos, ambos han de ser tenidos en cuenta, por lo que podrían ser materia de futuras investigaciones. 